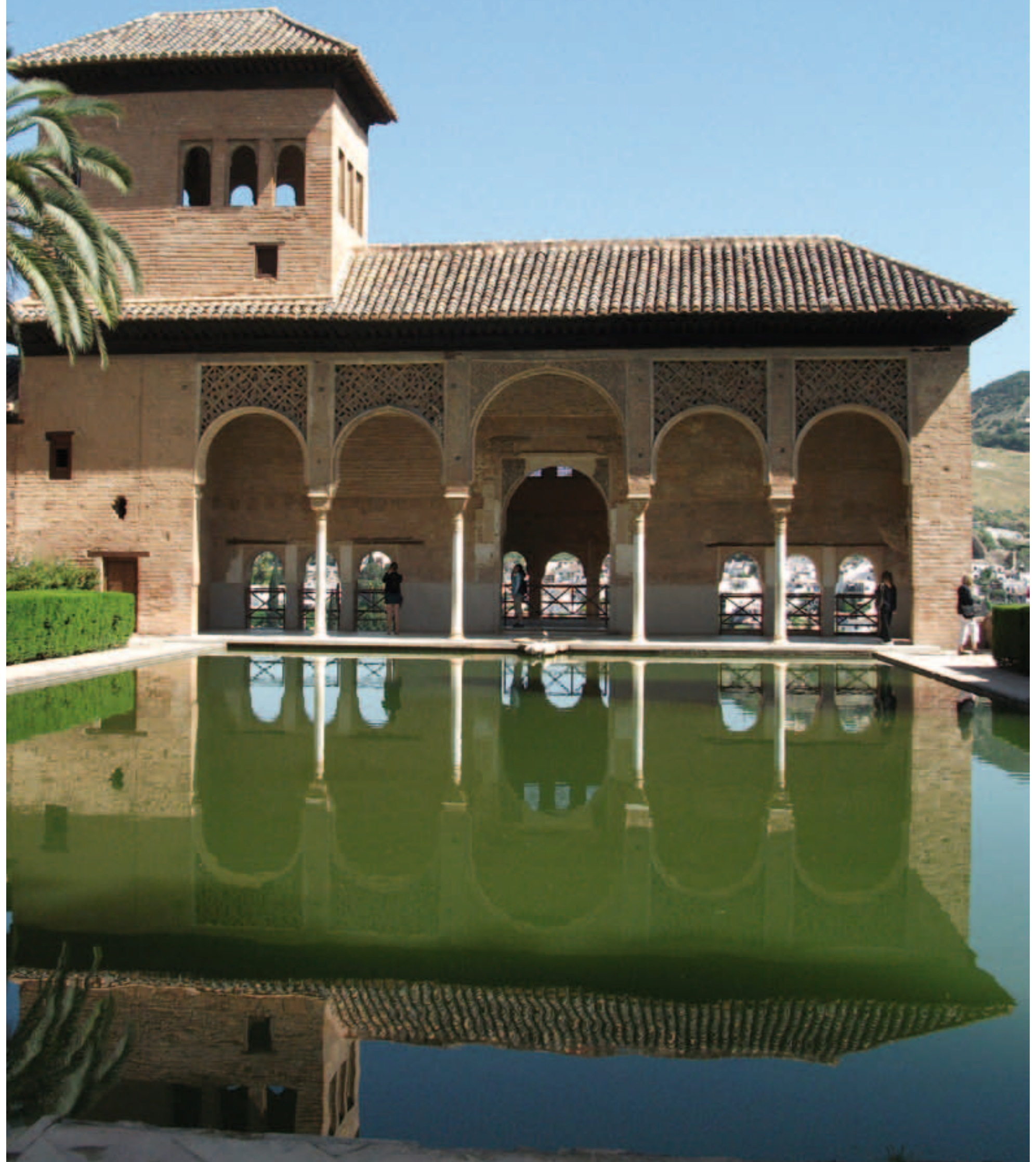




\section{Los valores del monumento restaurado. Una aproximación a la restauración científica}

Lucia Gómez Robles, arquitecta e historiadora del arte

\section{Resumen}

La restauración en nuestro tiempo es una disciplina que se aplica con una amplia variedad de criterios que llegan a ser incluso divergentes. Así pues encontramos intervenciones en monumentos históricos que suscitan opiniones completamente opuestas y que son a la vez excelentes o indecentes dependiendo del punto de vista de la persona que opina. Sin embargo la restauración no debería ser una actividad sometida al capricho de quien la practica porque, de hecho, reconocemos unánimemente la validez de los grandes ejemplos de intervenciones como la del Colosseo o el Arco de Tito en Roma o el Palacio del Partal en Granada. Algo subyace en aquellos proyectos que debería mantenerse en nuestra restauración actual, un algo que no es cuantificable, pero que se puede cualificar.

Este artículo trata de desentrañar la parte más objetiva y, por tanto, científica, de la restauración buscando un modo más imparcial de valoración de la misma y, a la vez, un criterio razonado de aproximación a la intervención a través de la preservación de los valores del monumento, tanto intrínsecos como adquiridos. Se analizará cómo dichos valores se salvaguardaron en las intervenciones que consideramos modélicas del mismo modo en que hoy también lo hacen otros proyectos de amplia aceptación, y se aportará una relación de ellos y su importancia, porque sólo garantizándolos es posible una buena restauración.

Se propone, por tanto, una hipótesis metodológica que sirva tanto para analizar como para proponer intervenciones y tratar de devolver al camino de la ciencia a la restauración y a la historia de la arquitectura.

\section{Palabras clave}

Conservación / Metodología / Monumentos / Patrimonio cultural / Patrimonio inmueble / Restauración / Teorías / Valoración 
¿Hubo alguna vez una "restauración a la española"? Se preguntaba Antoni González en la sesión inaugural de la IV Bienal de Restauración Monumental (GONZÁLEZ MORENO-NAVARRO, en prensa). Sin duda es una cuestión controvertida, como controvertida es la restauración misma, especialmente en nuestros dias. Y es que, tanto en el campo nacional como en el internacional, se atraviesa un momento de crisis conceptual que no existía en otras épocas. En los últimos tiempos la disciplina se ha despojado de los términos absolutos de los que había gozado en otros periodos pero, a cambio, el relativismo con el que ahora se afronta pone en peligro, demasiado a menudo, a los monumentos.

Este artículo surge de la reflexión sobre la restauración del teatro romano de Sagunto realizado en la ya mencionada IV Bienal de Restauración Monumental (GÓMEZ ROBLES; QUIROSA GARCÍA, en prensa). En aquel discurso se buscaba el análisis crítico de la intervención en función de los valores del monumento y ahora hago extensible ese análisis a otros casos para buscar una perspectiva general que contribuya a clarificar el panorama de la restauración actual.

En el largo recorrido de la senda de la restauración desde los comienzos hasta la actualidad, hemos aprendido que cada restauración es diferente a las demás, que tiene sus propias complejidades sus características particulares y sus condiciones únicas e irrepetibles, y por ello cada caso debe de estudiarse desde parámetros distintos, pero ¿podemos enfrentarnos a la restauración de una forma arbitraria exclusivamente dependiente del criterio subjetivo de cada arquitecto? Afortunadamente se ha generalizado la realización de estudios previos y la formación de equipos pluridisciplinares, más que interdisciplinares, pero no siempre los resultados de estos estudios ni las aportaciones de otros profesionales son todo lo determinantes que debieran en el proyecto final.

Así pues sigue existiendo arbitrariedad amparada en la singularidad del monumento histórico. Y sin embargo podemos afirmar que existe un modo "correcto" de restaurar. Lo podemos ver en los ejemplos, ya míticos, del Arco de Tito, del Coliseo o del Partal, ejemplos que seguimos admirando y estudiando, ratificados por el paso del tiempo. Quizás se podría pensar que ese tipo de intervenciones son propias de otra época y que ya no son posibles en nuestros dias, pero permitaseme añadir a esos ejemplos otros actuales que confirman que se puede hacer una adecuada restauración hoy y que entre aquellas y éstas hay un sustrato común cualitativamente objetivable. Mencionaré los casos de la restauración del teatro romano de Orange y de las casas romanas de Herculano llevadas a cabo por la British School en Roma en el llamado Herculaneum Conservation Project (HCP).

Pero decía que existe un sustrato común a esas intervenciones que es objetivable. Ese sustrato no es otro que el de los valores de cada uno de estos edificios que las restauraciones contribuyen a devolver o reforzar. Sin embargo, ¿qué es "valorable" en un edificio histórico? Por "valor" entiende la RAE aquella "cualidad que poseen algunas realidades, consideradas bienes, por lo cual son estimables (...) tienen polaridad en cuanto son positivos o negativos, y jerarquía en cuanto son superiores o inferiores".

Si pensamos en un ejemplo concreto, pongamos por caso un teatro romano clásico, la respuesta más inmediata, a pesar de su relativamente reciente aceptación, es quizás su valor como documento histórico que proviene de otra época y acumula información hasta el momento presente. El segundo aspecto más obvio es probablemente su valor artístico ligado a su decoración o su "forma", pero también a su tipología, al espacio que conforma y al modo en que lo hace. En el caso de nuestro teatro se trataría de los órdenes arquitectónicos que constituyen la escena, pero también su configuración semicircular y cerrada, su distribución jerarquizada, la disposición de sus accesos y todo el resto de elementos que definen el edificio en una determinada época y lugar. El siguiente elemento probablemente sería su valor simbólico, es decir, su importancia y su significado para la población que lo acoge, y a partir de aqui aparece una serie de valores acaso menos evidentes pero igualmente relevantes. Existe una estructura muy característica de la época romana, una forma de construirla propia de la localidad en la que se encuentra, una función que el edificio acoge y que está intimamente ligada a la sociedad y la cultura romanas y una estética o imagen general que lo hace reconocible.

Individualmente ofrecen una específica información sobre el monumento y en conjunto le aportan su sentido completo al definirlo desde todos sus matices. Por tanto, estos valores son reconocibles en todo edificio histórico y deben ser preservados para garantizar una buena restauración y para ello es necesario conocerlos y reconocerlos claramente. Los analizaremos con detalle.

\section{- El valor tipológico}

Es el valor que responde a la tipología, es decir, al tipo arquitectónico depurado a lo largo del tiempo para albergar una determinada actividad. Sus características varían según la época y la geografía incluso para una misma función. Se adapta a las necesidades de la sociedad que la utiliza, responde a una determinada civilización o cultura y conlleva unas determinadas condiciones espaciales, lumínicas, ambientales, relacionales entre distintos espacios, visuales, etc.

Su recuperación es importante porque da sentido a la construcción y explica el entorno al que perteneció en tanto en cuanto responde a unos determinados requerimientos. Es, probablemente y junto con el formal, el valor más ligado a la civilización que lo generó o adaptó de otros porque ayuda a identificarla y a describirla.

Es una variable geográfica y temporal porque es diferente en función del lugar y el tiempo en que surge, independientemente de que la actividad que acoja sea la misma, y por tanto caracteriza el territorio y el periodo. Por ejemplo una terma romana y una terma islámica, teniendo la misma función, tienen desarrollos tipológicos distintos, cada uno en una época, de la misma forma que una terma hispa- 
nomusulmana y una terma otomana, aproximándose más entre sí, tienen características específicas ligadas a su localización geográfica.

\section{- El valor estructural}

El valor estructural de un edificio encierra en sí la sabiduría técnica de una sociedad, saber que procede de los continuos ensayos y errores hasta alcanzar el dominio técnico que permite proyectar el espacio con seguridad. Implica un control sobre los materiales disponibles en una determinada época y lugar y un entendimiento de cierta profundidad en la tecnología que entraña una reflexión que ilustra el nivel intelectual de una civilización.

Se trata de una variable temporal dentro de una misma área geográfica más o menos amplia, ya que tiende a emplearse el mismo sistema estructural dentro de lo que Ilamamos un "estilo". Caracteriza el tiempo o el periodo al utilizar durante una época un mismo sistema estructural, como la bóveda de cañón sobre gruesos muros portantes durante el románico.
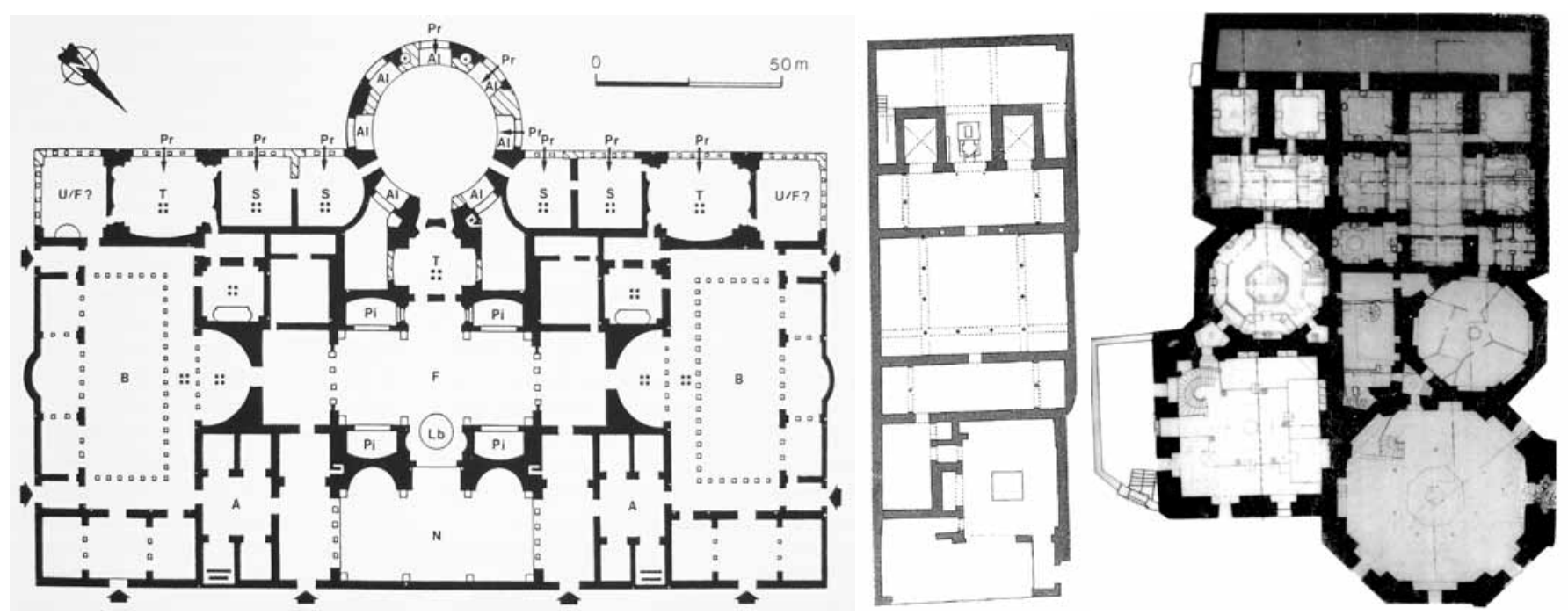

De izquierda a derecha, termas romanas de Caracalla, del siglo III d. de C. Fuente: GROS, 2001 : 451 ; baños del Nogal o bañuelo en Granada, siglo XIV, según dibujo de Manuel Gómez Moreno. Fuente: EPALZA, 1989: 51; baños turcos de Bey-Hammam de Tesalónica, siglo XV. Fuente: http://en.wikipedia.org/wiki/File: THES-Bey_Hamam_plan.jpg. Plano publicado bajo GNU Free Documentation License, v. 1.2 o cualquier otra que posteriormente publique la Free Software Foundation
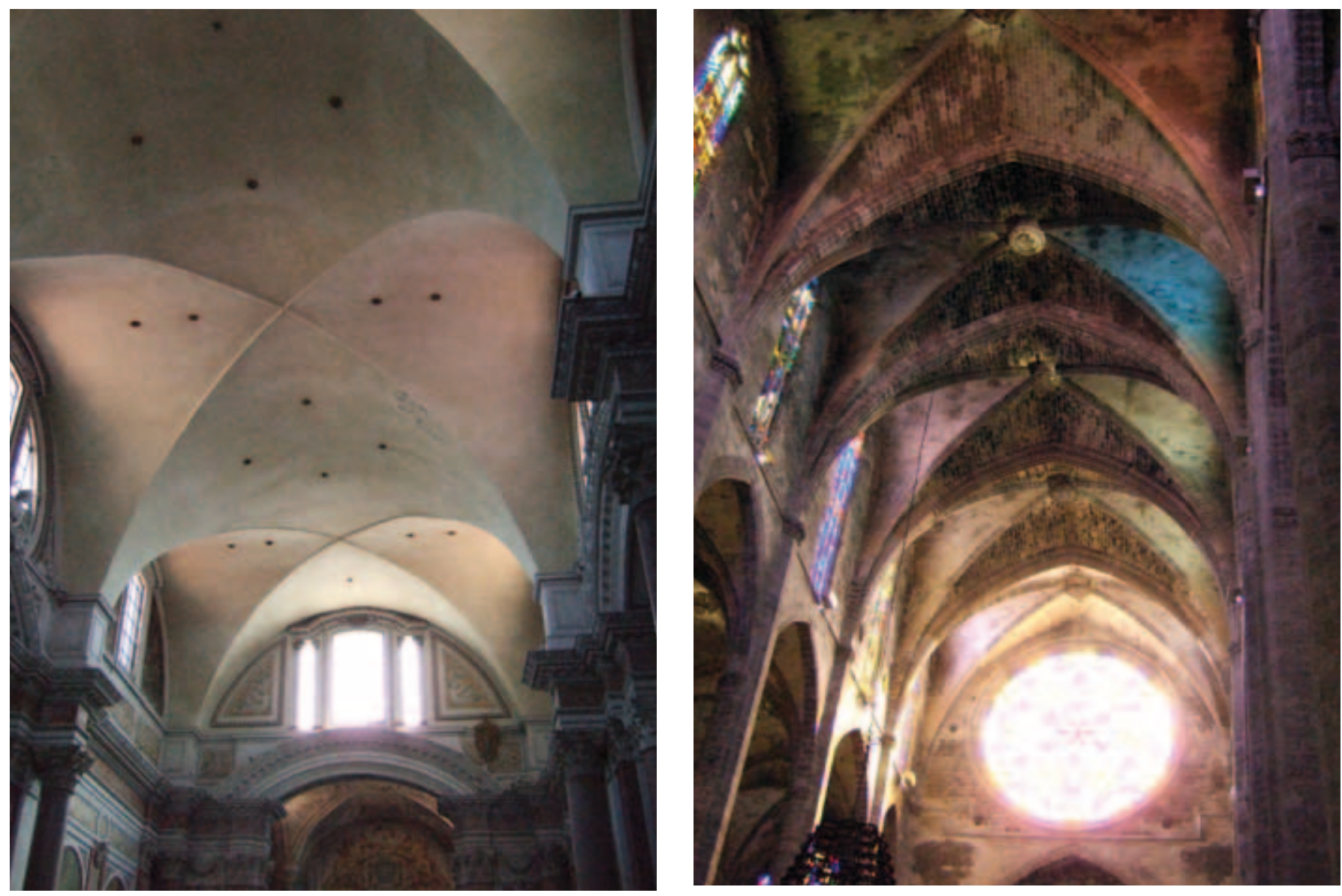

A la izquierda, bóvedas de arista de Santa Maria degli Angeli (Roma), antiguas termas de Diocleciano (siglo IV) convertidas en iglesia por Miguel Ángel (siglo XVI). A la derecha, nave central de la Catedral de Palma de Mallorca (siglo XIV). Fotos: Lucía Gómez Robles 


\section{El saber constructivo es más}

cambiante que el estructural

y depende de las disponibilidades

locales de materiales (...) la tapia o

tapial en España ha sido utilizada por

todas las culturas hasta el siglo XIX

desde época romana

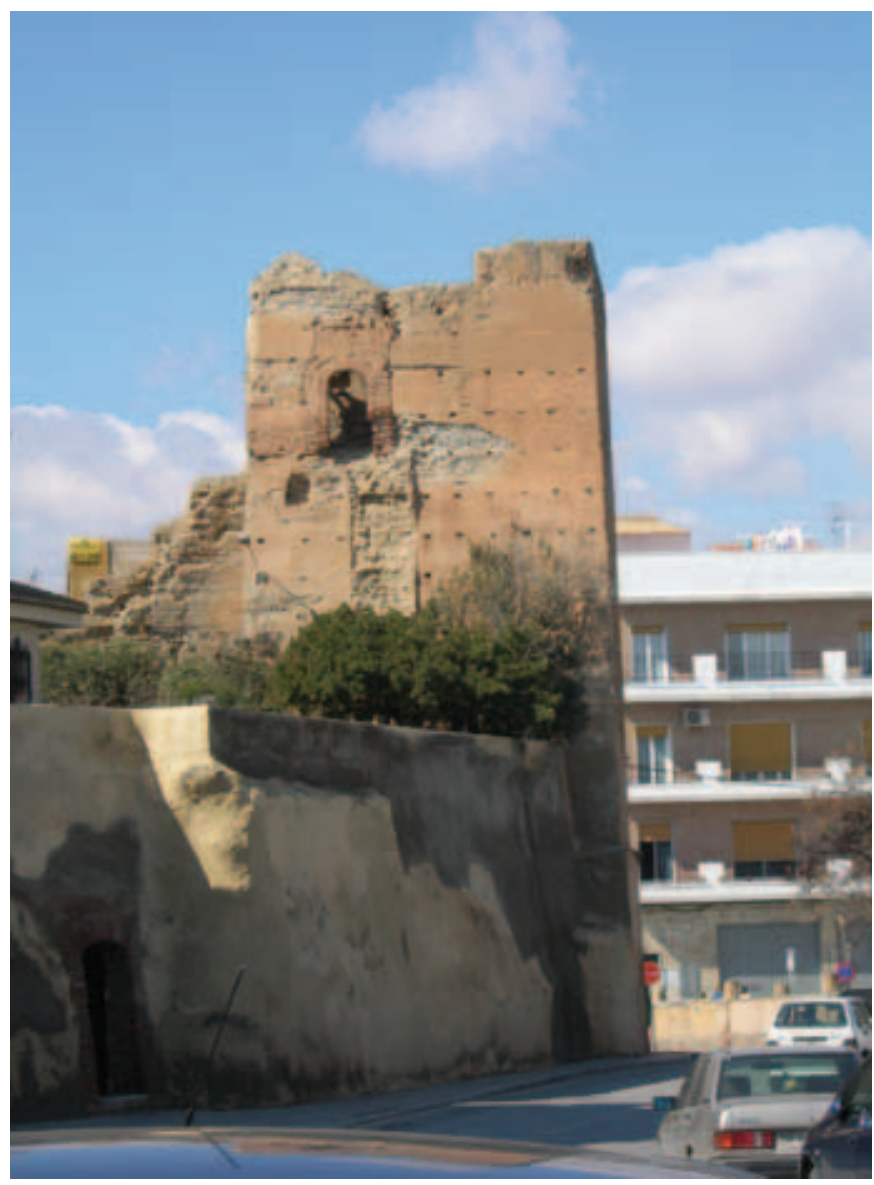

Torreón del Ferro (siglo XI) en Guadix (Granada). Foto: Lucía Gómez Robles

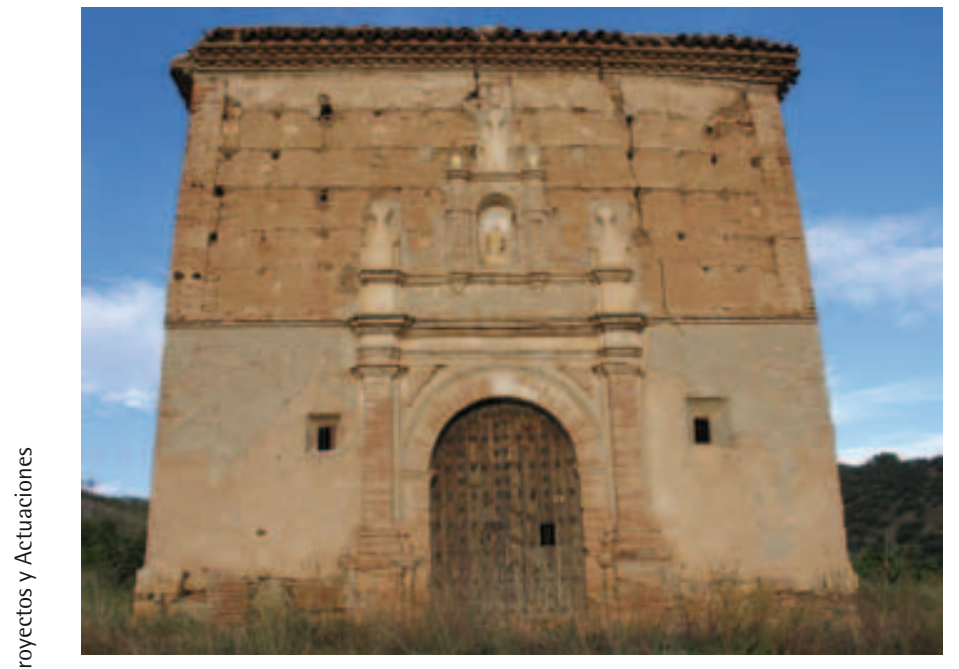

Ermita de la Virgen de los Dolores de Baguena (Tervel), del siglo XVIII. Fuente: Centro de Estudios del Jiloca
- El valor constructivo

El valor constructivo está intimamente ligado al estructural, pero tiene características propias. Diferentes sistemas constructivos pueden dar lugar a sistemas estructurales semejantes, como una bóveda de arista de hormigón romano y una bóveda de crucería de sillería gótica, aunque su comportamiento físico vendrá matizado por el material.

El saber constructivo es más cambiante que el estructural y depende de las disponibilidades locales de materiales, lo que hace que presente frecuentes variabilidades geográficas. En cambio es más estable al tiempo, por lo que se presenta a menudo como una variable geográfica y caracteriza el territorio. Es habitual que en una misma área geográfica distintas culturas que desarrollan sistemas estructurales diferentes mantengan estable el modo constructivo y los materiales propios de la zona. Por ejemplo la tapia o tapial en España ha sido utilizada por todas las culturas hasta el siglo XIX desde época romana, e incluso se han documentado algunos tapiales de época púnica, a finales de la Edad del bronce.

- El valor funcional

El valor funcional es esencial en la arquitectura. Es el rasgo que la diferencia del resto de las grandes artes, escultura y pintura, fundamentalmente contemplativas. La función, no obstante, puede verse modificada a lo largo del tiempo, puede mantenerse con alteraciones o puede desaparecer. Los edificios nacidos para albergar actividades aún existentes hoy en día, como el teatro en la tradición occidental, admiten una readaptación conceptualmente muy sencilla. Cuando la actividad desaparece o evoluciona tanto como para necesitar grandes transformaciones en el edificio es necesario estudiar la compatibilidad del nuevo uso, ya que no todos los edificios son capaces de readaptarse a cualquier tipo de función y en ese proceso de adaptación puede acabar desapareciendo la esencia de los mismos.

En cualquier caso la "objetualización" de la arquitectura, al dejarla sin uso alguno, la aleja de su esencia y en ocasiones puede condenarla al abandono si su valor no es suficiente para atraer la atención como objeto observable o contemplable, un problema especialmente marcado en una época como la actual de sobreabundancia de museos y edificios-museo.

La función es una variable cultural, ligada a la sociedad que la realiza. Existen funciones universales como la residencia que, en cualquier caso, quedan matizadas por cada civilización con unas peculiaridades de carácter cultural y otras de carácter climatológico, es decir, adaptándose a las costumbres y al clima de cada sociedad y lugar.

Existen también determinadas funciones que, siendo esenciales en la comprensión de una época o civilización concretas, son completamente desconocidas en otras. Es el caso del teatro clásico, tan propio de las culturas griega y romana, aunque con 
características muy diferentes, que es completamente desconocido para la islámica donde ni siquiera existe el concepto de dramaturgia.

\section{- El valor estético}

El valor estético corresponde a la "dignidad" del edificio. En ocasiones éste se ve afectado por situaciones que mutilan la construcción, normalmente desastres naturales o provocados, como un incendio, que aceleran la destrucción de la estructura y provocan colapsos en cadena que desfiguran la imagen original del edificio, mientras que el paso normal del tiempo tiende a generar un desgaste más homogéneo.

Salvaguardar el valor estético del edificio implica un mantenimiento o recuperación de sus elementos fundamentales, tanto para la conservación más básica como para su identificación, es decir, una reparación de su volumetría más elemental que permita entrever su estado original.

Es una variable subjetiva individual, ligada en realidad a los conocimientos previos del espectador que extraña las partes faltantes del edificio o sus añadidos porque posee una imagen previa adquirida a través del estudio del mismo o de aquellos semejantes a él. Se podria ejemplificar con el caso de un arco en el que sólo quedan los estribos y los arranques del mismo. El espectador que sabe qué y cómo es un arco extraña las dovelas perdidas porque su recuerdo del mismo reconoce la estructura desaparecida.

\section{- El valor formal}

El valor formal es el otorgado al edificio por la decoración y en ningún caso es baladi. En ocasiones este elemento es de una altísima relevancia, como en el caso de la arquitectura hispano musulmana, y en especial se podría señalar la nazari, donde la estructura es casi mero soporte de la decoración.

La ornamentación cualifica la arquitectura de toda época, incluso la ausencia intencionada de ella caracteriza un determinado período, y aporta la significación cultural más relevante al evidenciar los mensajes más claros de la sociedad que la ejecuta. Completamente despojada de ella el edificio se lee de un modo erróneo, convertido en un esqueleto al que el revestimiento puede darle infinitos aspectos diferentes.

Su conservación, su recuerdo evidenciado de algún modo en la intervención es, por tanto, fundamental para la interpretación correcta de la arquitectura. Como la función, es una variable cultural y a menudo se relaciona, aunque sea en parte con ella. Responde a una determinada civilización que utiliza un específico sistema decorativo pero a la vez introduce ocasionalmente elementos relacionados con la función que alberga el espacio decorado. Se podrían citar cientos de ejemplos, como las tumbas egipcias que se decoran con imágenes que ilustran los pasajes del Libro de los muertos.

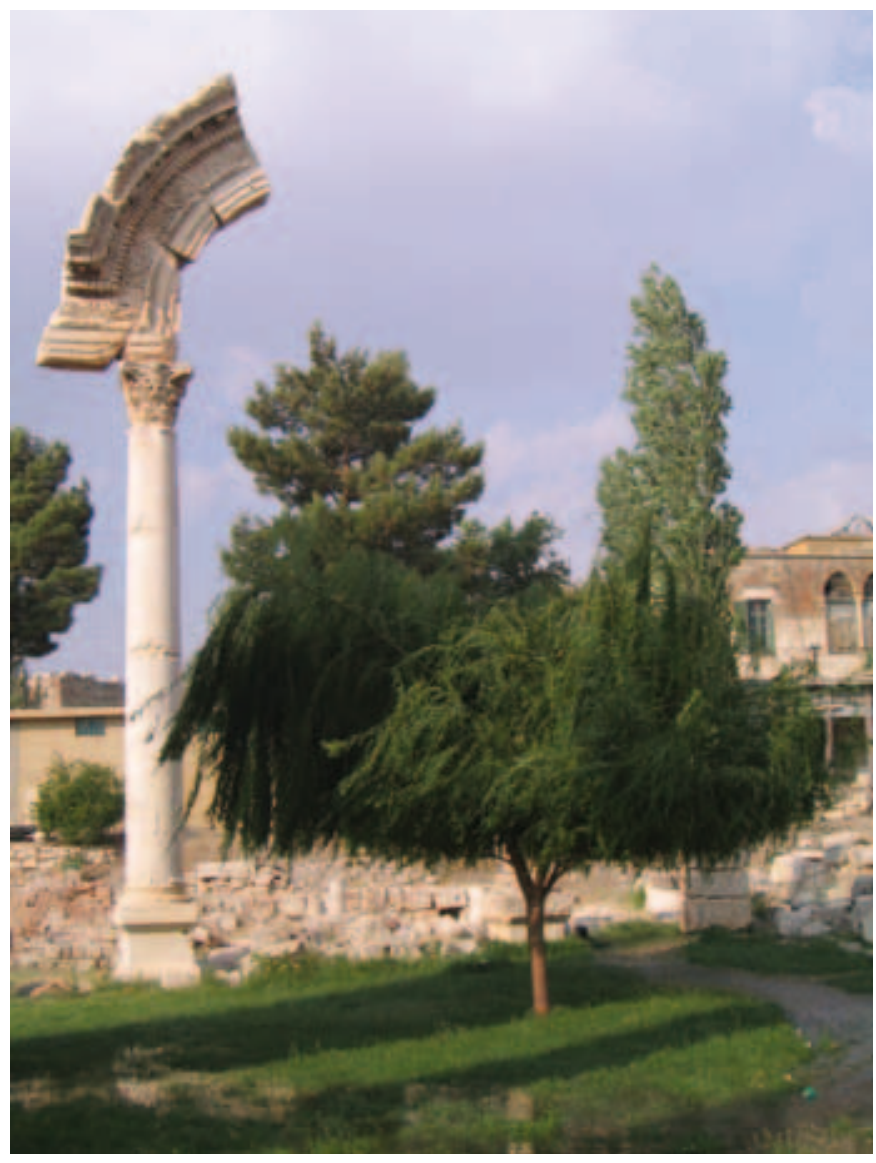

Fragmento de arcada de la segunda mitad del siglo II d. de C. en las ruinas de Baalbek, Libano'. Foto: Daniel Lohmann

\section{- El valor histórico}

El valor histórico es la historia del edificio desde su origen, desde los inicios de su construcción hasta el momento actual, incluida la destrucción del mismo cuando ésta se produce, y cuya huella en ocasiones ha desaparecido mientras en otras puede leerse en parte o en su totalidad.

Ese valor documental debe ser salvaguardado porque encierra no sólo la historia del edificio, sino la de la sociedad que lo erigió y la de aquellas que lo disfrutaron y transformaron en épocas posteriores. A menudo la información que ofrece se complementa con otros tipos de documentos conservados que ayudan a explicar el propio edificio mejorando la comprensión del mismo gracias a la contribución de las diferentes fuentes. Es el caso de la Basílica de San Pedro de Roma, cuya historia seria incomprensible sin la cuantiosa información guardada en los archivos. Del mismo modo, a veces es el edificio el que aporta la luz a la oscuridad de otras fuentes. En su calidad de documento debe entenderse como un elemento más que adquiere su mayor claridad en la suma del total. Es una variable acumulativa que se inicia con el propio proyecto del edificio y se prolonga hasta el momento de su desaparición total.

\section{- El valor simbólico}

El valor simbólico es el carácter representativo del edificio histórico otorgado de forma más o menos consciente por la sociedad que lo 
acoge al identificarlo con un momento histórico relevante, con un sentimiento religioso o de identidad cultural de la población o cualquier otro signo del imaginario colectivo. Como símbolo, la imagen arraigada cobra gran fuerza y cualquier alteración afecta sustancialmente en la opinión social. La restauración puede potenciar ese simbolismo o destruirlo, por ejemplo cuando se interviene sobre una ruina eliminando los elementos propios del abandono como la vegetación, la pátina del tiempo o la inaccesibilidad. Con su pérdida desaparece también la imagen romántica que encarnaba.

Es una variable subjetiva-colectiva, que se adquiere con el tiempo y depende del grupo social que la genera, pudiendo llegar a mutar en la sucesión de generaciones o incluso desaparecer cuando se pierde la memoria de la comunidad.

Si analizamos ahora aquellas restauraciones que se mencionaban al inicio buscando esa esencia permanente que los une podemos observar cómo en cada uno de los casos se está produciendo una recuperación de algunos de estos valores, sin afectar a los demás.

\section{EL ANFITEATRO FLAVIO, EL COLISEO DE ROMA}

La obra de restauración (LUCIANI, 1990: 54-55), realizada a principios del siglo XIX, es uno de los hitos de la historia de la conservación de los monumentos. Realizada en dos momentos y por dos arquitectos distintos, Stern y Valadier, acometió de dos formas diferentes la solución del mismo problema. La imparable desintegración del cerramiento exterior del edificio, en gran parte debida al continuo expolio del material pétreo para su reutilización, muy agravada por el sismo de 1703 y las excavaciones realizadas entre 1805 y 1806 (JONSSON, 1986: 28-38), se detuvo por dos sistemas. En un extremo un enorme contrafuerte, como una mano gigante deteniendo el desplome, consolidó la estructura frenando el deterioro de la fábrica, macizando a la vez los huecos de las arcadas finales en las que las dovelas casi completamente desprendidas quedaban suspendidas por el relleno de ladrillo congelando el colapso. En el otro lado, se realizó la reintegración en ladrillo de varios módulos de arcadas, representando los órdenes arquitectónicos con una simplificación de los elementos decorativos que enfatizaba, junto con el uso de un material claramente diferente, la intervención de restauración.

En este caso el problema era detener la rápida descomposición de las fábricas del edificio, pero de él quedaba, no sólo lo suficiente para entender la tipología del anfiteatro clásico, sino incluso para mantener su uso para espectáculos con una sencilla cubierta de madera sobre la antigua arena. Las nuevas estructuras, además, se comportaban según las reglas de las originales, con el mismo sistema de contrarrestos, apoyándose sobre ellas y permitiéndoles continuar trabajando al restablecer las partes faltantes que desequilibraban la estructura original dañada por el expolio. El sistema constructivo era el mismo, únicamente modificando el material pétreo por el cerámico en el exterior, siendo por otra par- te el ladrillo un material fundamental en las estructuras interiores de la construcción original.

Las dos intervenciones contribuian a devolver en parte la estética al edificio, es decir, diluir algo esa sensación de edificio mutilado que la acción destructiva del ser humano tiene sobre los edificios (comparable sólo a las catástrofes naturales), pero además, la de Valadier tenía la virtud de recuperar la forma original al disponer de nuevo los órdenes superpuestos tan importantes en el lenguaje arquitectónico clásico y romano. La de Stern en cambio permitía evidenciar la historia del edificio haciendo muy patente el episodio final del terremoto y la degradación debida a un expolio de materiales que se prolongó durante siglos convirtiendo al anfiteatro en la mayor cantera de la ciudad de Roma.

En realidad ambas intervenciones fueron fruto de las circunstancias; de la prisa, en el caso de Stern, que se vio enfrentado a la necesidad de intervenir urgentemente para evitar el colapso del lado oeste; y de la falta de medios económicos, en el de Valadier, que debió conformarse con realizar en travertino, y de forma idéntica a los originales, exclusivamente los capiteles y las basas de los órdenes.

En cualquier caso las intervenciones reforzaron la imagen del edificio como símbolo de la ciudad de Roma. Por tanto vemos que ambas intervenciones consiguieron fortalecer varios de los valores del edificio: el estructural, el constructivo, el estético, el formal, el histórico y el simbólico, sin perjudicar ni el tipológico ni el funcional.

\section{EL ARCO DE TITO}

Otro caso paradigmático de la historia de la restauración es el Arco de Tito. Situado en los foros de Roma sufrió una restauración a principios del XIX a cargo de nuevo de Valadier (TESTA, 1996: 46), que intervino sobre el arco con un proyecto que consistió en la liberación del edificio que se encontraba encastrado en una estructura defensiva medieval y en la reconstrucción completa en ladrillo del núcleo, en muy malas condiciones según Valadier, y de los elementos desaparecidos realizados en travertino y simplificados respecto a los originales de mármol.

La intervención recuperó la tipología del arco de triunfo como hito urbano al devolverle su aspecto de edificio exento, permitiendo observarlo del modo en que se hacía en origen. Dicha imagen de hito urbano aislado, con una profusa decoración e información de carácter figurativo, está en la esencia misma del arco de triunfo que nace en la República ligado a la muralla y a los accesos y que con el Imperio asume un carácter independiente, marcando el paso sobre las vías más importantes para honrar las victorias del emperador y recordar a la población romana su poder, en uno más de los ejercicios propagandísticos del gobierno de Roma. Una tipología que, para finales del s. I d. C., ya estaba completamente definida y que no se entendía sin los órdenes arquitectónicos que 

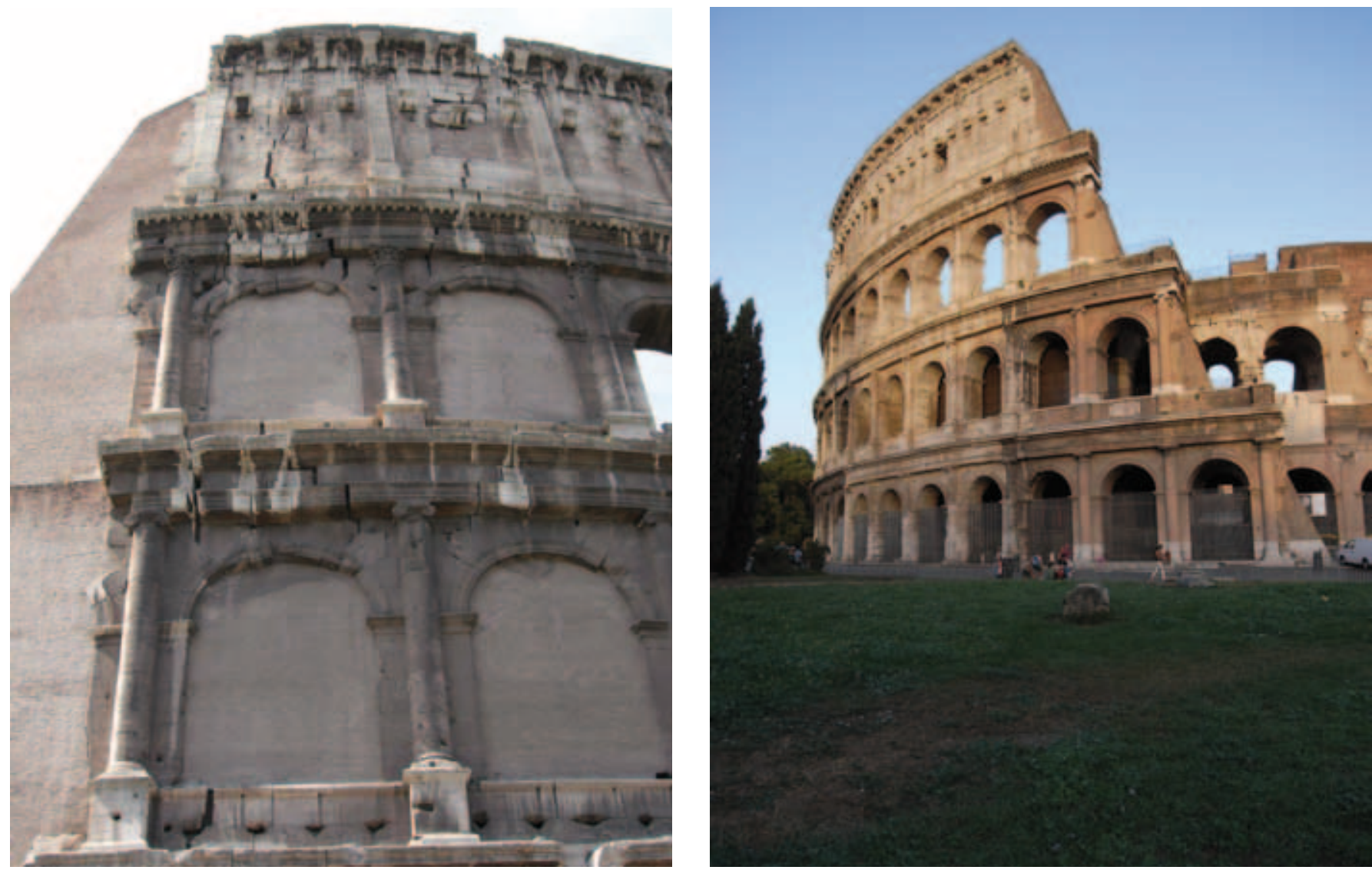

Coliseo de Roma. Intervenciones de principios del siglo XIX. A la izquierda, de Stern, y a la derecha, de Valadier. Fotos: Lucía Gómez Robles (izda.) y Juan Miguel Quirosa (dcha.)
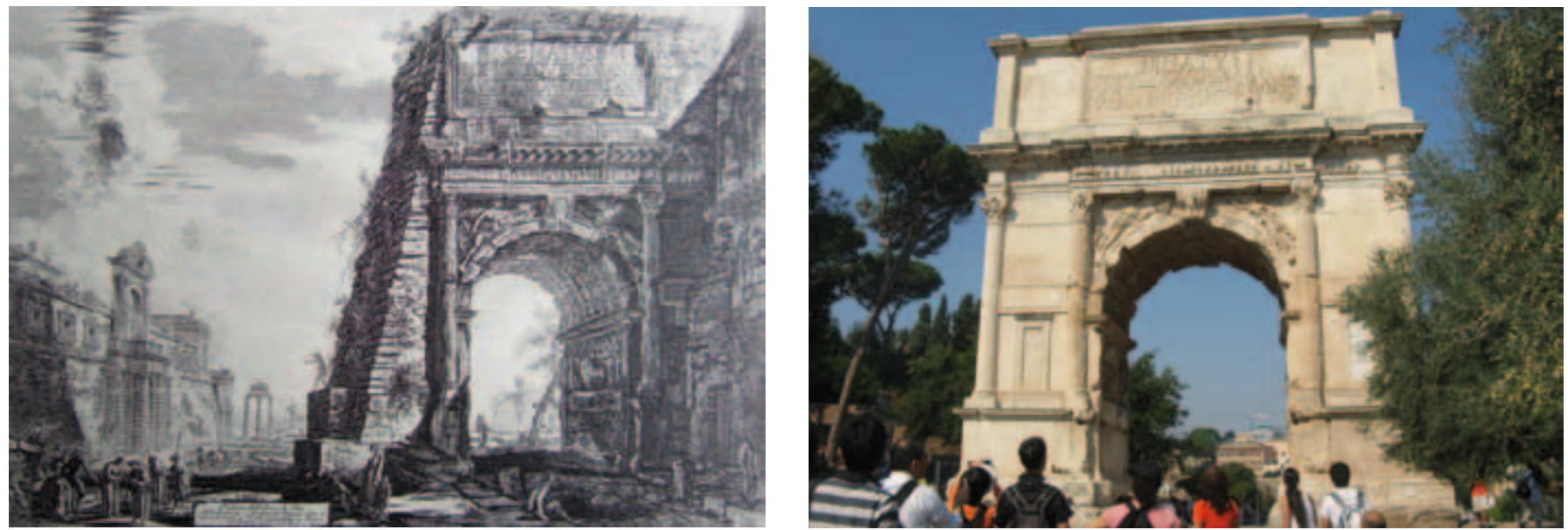

A la izquierda, Arco de Tito (s. I d. de C.) antes de la intervención, grabado de Piranesi en "Veduta del Arco di Tito", de Vedute di Roma, 1778. Fuente: FICACCl, 2006: 325. A la derecha el Arco de Tito tras la intervención de Valadier. Foło: Lucía Gómez Robles

Podemos afirmar que existe un modo "correcto" de restaurar. Lo podemos ver en los ejemplos, ya míticos, del Arco de Tito, del Coliseo o del Partal, ejemplos que seguimos admirando y estudiando, ratificados por el paso del tiempo 


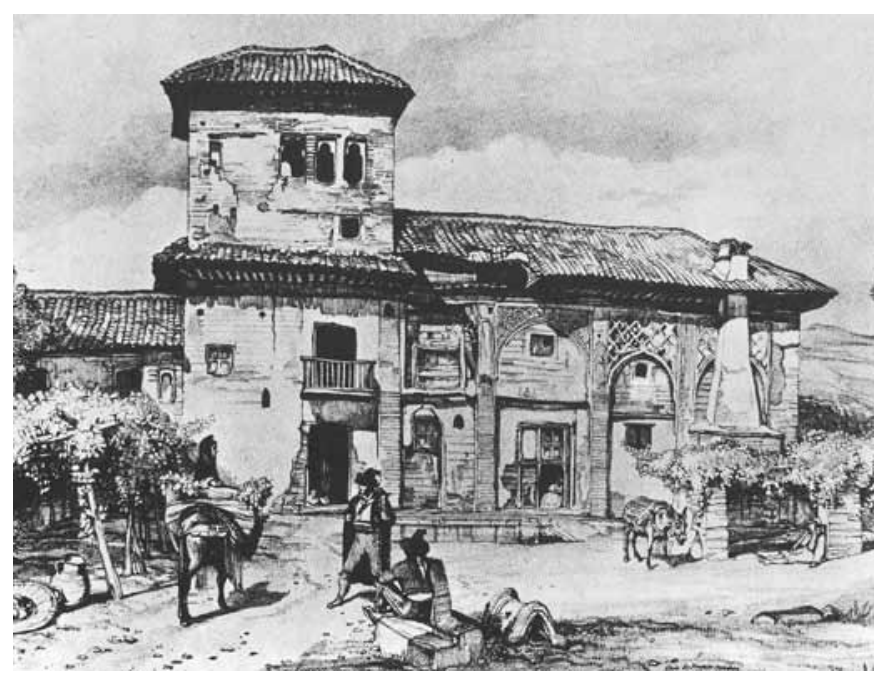

Vista de Lewis de la Torre de las Damas en 1833, Sketches of Spain. Fuente: GALLEGO BURÍN, 1996: 112

estructuraban la composición y lo equiparaban con otras edificaciones de carácter público. No obstante, seguiría evolucionando hasta los ejemplos de triple vano como los de Septimio Severo o Constantino, también situados en los foros.

Esta restauración, como la que Valadier realizó en el Colosseo, cambiaba el modo habitual de intervención italiano coincidiendo con el periodo de dominación francesa en Roma. Los trabajos devolvieron al arco su unidad figurativa al recomponer las partes faltantes, recuperando la imagen completa y a la vez subrayando el aspecto decorativo al reincorporar, aunque fuese de modo simplificado, los elementos principales de los órdenes, aspecto fundamental en una construcción tan sencilla desde el punto de vista espacial y estructural.

No obstante, desde el punto de vista histórico, se canceló todo rastro de la fase medieval que ha quedado exclusivamente reflejada en los documentos contemporáneos a la intervención, a favor del carácter simbólico del edificio.

A diferencia de lo que ocurría en la intervención del Colosseo, en este caso se reforzaron los valores tipológico, funcional, estético, formal y simbólico, se modificó el constructivo al sustituir el núcleo, que se realizó en un material diferente manteniendo el mismo tipo de estructura, y se actuó en contra del valor histórico. Este caso, mantener el valor histórico implicaba renunciar a los cinco que se recuperaron y, en todo caso, se consideró que la construcción medieval carecía de la importancia suficiente para mantenerla. Esta decisión hace que la restauración no sea óptima, sin embargo sus aportaciones son de una incuestionable validez.

\section{EL PALACIO DEL PARTAL}

Pero además de los célebres casos italianos, en España existe una restauración particularmente aplaudida. Se trata del Palacio del Partal, el más antiguo del conjunto de la Alhambra. Este edificio

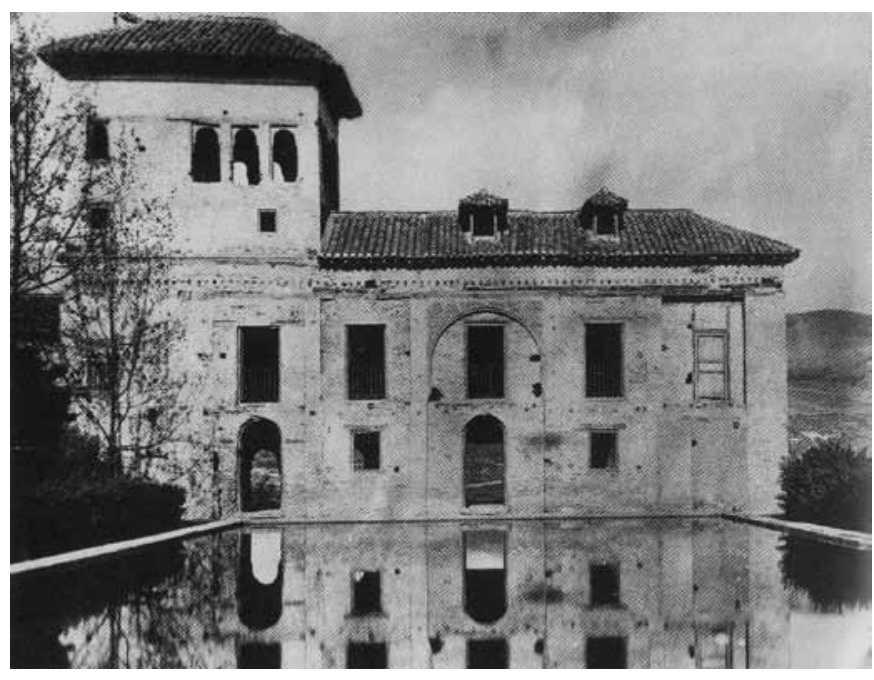

El Partal (siglos XIII-XIV) antes de la restauración de 1923 de Torres Balbás. Fuente: ESTEBAN CHAPAPRIAA, 2008: 84-85

se alza sobre la muralla del recinto con un cuerpo avanzado que se abre al paisaje y un pórtico interior frente a la gran alberca. A principios del siglo XX, sin embargo, estaba colonizado por varias viviendas que desfiguraban el aspecto inicial del edificio.

La restauración llevada a cabo por Leopoldo Torres Balbás en 1923 eliminó todos los añadidos populares y recuperó la imagen original del palacio poniendo especial atención a la decoración del pórtico. Las obras consistieron en la limpieza de los paramentos y del techo, del que se eliminó la pintura moderna, y la recolocación de la parte central del pórtico que se encontraba desplomada $20 \mathrm{~cm}$. Esta operación llevó consigo una intervención, más desconocida, de refuerzo del forjado y la cubierta con la colocación de una viga metálica interior a todo lo largo del pórtico y viguetas de doble T sobre el techo del pórtico, en una actuación muy propia de la época.

Sin embargo, si esta intervención es reconocida universalmente es por la solución tomada en la recuperación de las albanegas de los arcos del pórtico. De los cinco que constituyen el frente, tan sólo el central se había conservado mientras que el resto había desaparecido. Apoyándose en el dibujo de John Frederik Lewis realizado en 1833, Torres Balbás tomó la decisión de restituir los arcos originales imitando la disposición primitiva de los rombos decorados sustituyéndolos por trozos de yeso agujereados que a cierta distancia daban la misma sensación que la decoración original. Además incluyó en uno de los rombos un fragmento de la yeseria antigua para dar una idea de la disposición primitiva y dispuso unas pilastras para soportar la arqueria, a falta de pruebas evidentes que demostraran la existencia previa de columnas (TORRES BALBÁS, 1965: 85-86). Dichas pilastras, no obstante, fueron posteriormente sustituidas a pesar de que no fueron encontradas nuevas evidencias que contradijesen la hipótesis de Torres Balbás.

La intervención recuperó en parte las formas decorativas del edificio, sin mentir sobre ellas, le devolvió su estética general tan desvirtuada por las adiciones del siglo XIX y evidenció la tipología palaciega hispanomusulmana recobrando la imagen de balcón sobre 


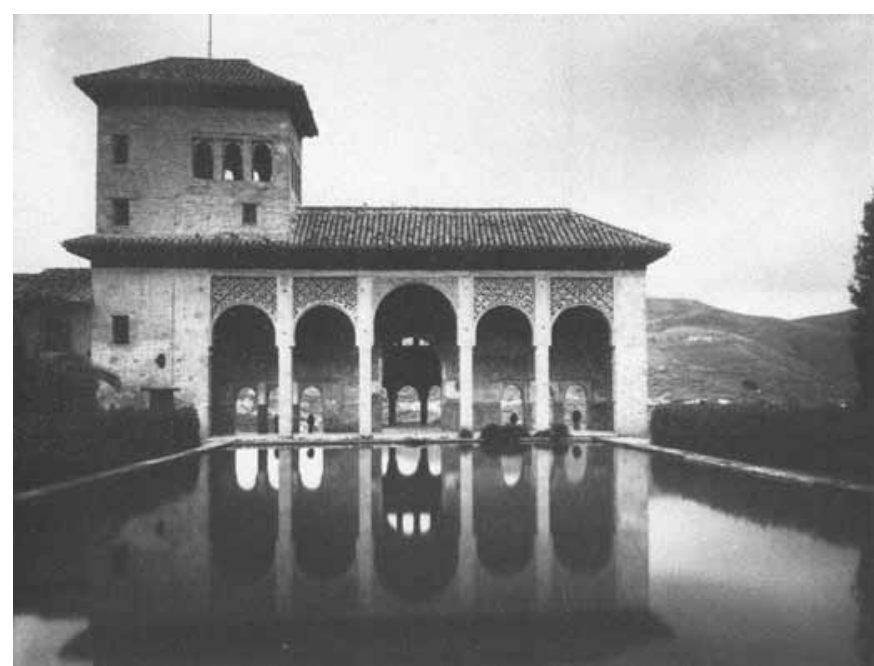

El Partal (siglos XIII-XIV) después de la restauración de 1923 de Torres Balbás. Fuente: ESTEBAN CHAPAPRIA, 2008: 84-85

el paisaje al exterior y de apertura al jardín al interior, permitiendo entender de un modo más claro el funcionamiento del palacio.

El proyecto, por tanto, aportó claridad y coherencia al edificio. Sin embargo, para ello fue necesario sacrificar una parte de la historia del mismo al cancelar su episodio más reciente con la demolición de las adiciones decimonónicas, algo de lo que el arquitecto era completamente consciente en el proceso: "El autor de la reparación lamenta haber expulsado de éste, como de otros lugares de la Alhambra, los trasgos y fantasmas, pobladores de las viejas construcciones ruinosas y abandonadas. Los que así las conocimos sentiremos siempre la nostalgia de su anterior etapa..." (TORRES BALBÁS, 1982: 191)

Tampoco la estructura fue recuperada en su forma original, sino que se desvirtuó con la introducción de los elementos metálicos ya mencionados, pero en su conjunto la intervención consiguió aportar numerosas cualidades al edificio restaurado. En este caso, como en el del Arco de Tito, el valor histórico fue el peor tratado en la restauración, y esta vez la introducción de elementos estructurales modernos actuó también contra los valores estructural y constructivo, pero a cambio se recuperaron los valores estético, formal, tipológico, funcional y simbólico de forma ejemplar.

En realidad el uso de estructuras modernas era muy propio de la época e incluso quedó amparado por la Carta de Atenas $^{2}$ que se redactaría pocos años después, en 1931, pero probablemente su uso no hubiera sido necesario para la intervención. Sin embargo el valor histórico es el que más a menudo se ve alterado para conseguir la recuperación de los demás, requiriendo quizás un extra de ingenio por parte de los responsables de la restauración y en ocasiones unas condiciones particulares del edificio a intervenir.

\section{HERCULANEUM CONSERVATION PROJECT}

Pero además de aquellos ejemplos tempranos existen actualmente proyectos dignos de mención. En concreto el programa de con-

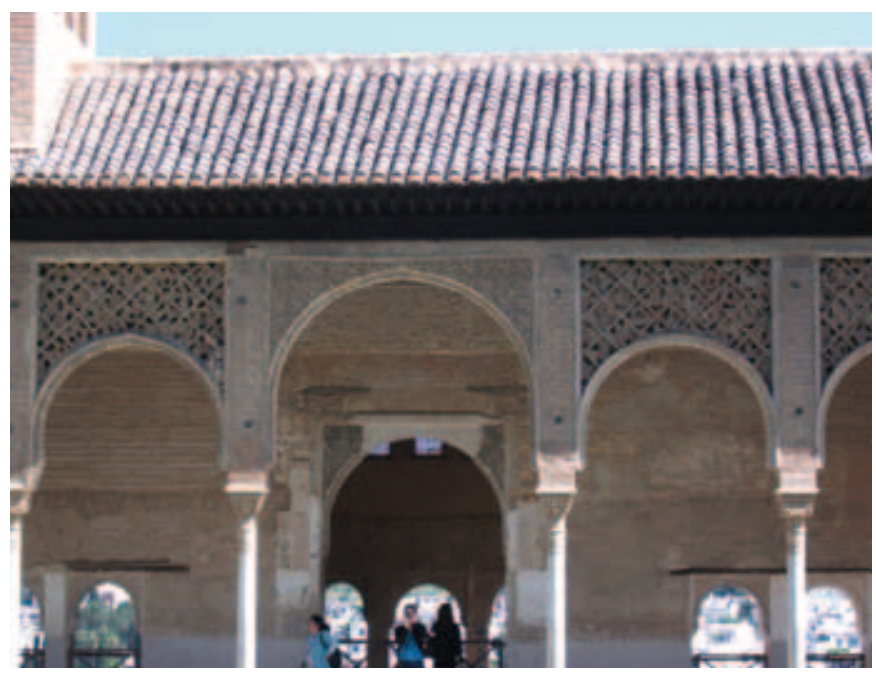

Detalle de las yeserías restauradas. Foto: Lucía Gómez Robles

servación de los restos arqueológicos de la antigua ciudad romana de Herculano interviene sobre estos de un modo igualmente admirable. El proyecto (PESARESI; RIZZI, 2007: 237-252) surgió ante la necesidad de conservar el inmenso patrimonio histórico artístico del sitio arqueológico que, en tiempos recientes, se había excavado indiscriminadamente y sin criterios de conservación de los restos desenterrados. Desde el comienzo tiene como objetivo principal frenar el deterioro de las estructuras conservadas y se está trabajando en la consolidación de fábricas y decoraciones y en la recuperación de los sistemas de saneamiento público y privado con el objeto de evitar los enormes daños causados por la acumulación de aguas en la ciudad romana en época de lluvias.

La actual Herculano se encuentra varios metros por encima de la clásica, que se dispone a sus pies en un gigantesco agujero que representa aproximadamente un cuarto de la ciudad original. La única solución posible para evitar los daños es la de evacuar toda el agua que se acumula en el gran hueco abierto por las excavaciones y por tanto nada mejor que reutilizar la propia red de saneamiento que se diseñó precisamente para ello. Esta reutilización, además de las canalizaciones, implica la recuperación de las cubiertas de las viviendas, perdidas en su totalidad en el incendio provocado por las cenizas del Vesubio.

La ventaja de la restauración en las edificaciones de Herculano es que gran parte de los muros portantes se mantienen en pie, incluso con sus decoraciones pictóricas, por lo que un sencillo saneamiento de la parte alta de los mismos permite la disposición de una nueva cubierta sin apenas modificar los restos conservados.

El ingenio del proyecto consiste justamente en la solución adoptada en la reconstrucción de las cubiertas, necesaria tanto para la reconducción de las aguas hacia las canalizaciones de saneamiento como para la protección de los abundantes frescos y mosaicos del sitio. El sistema usado es el de la recomposición de la cubierta con la misma geometría que en la estructura original, con el fin de obligar al agua a realizar el mismo recorrido previsto en las edificaciones originales. 


\section{En cada una de las restauraciones, no todos los valores se recuperan del mismo modo ni con la misma fuerza pero en todos los casos se logra restablecer varios de ellos}
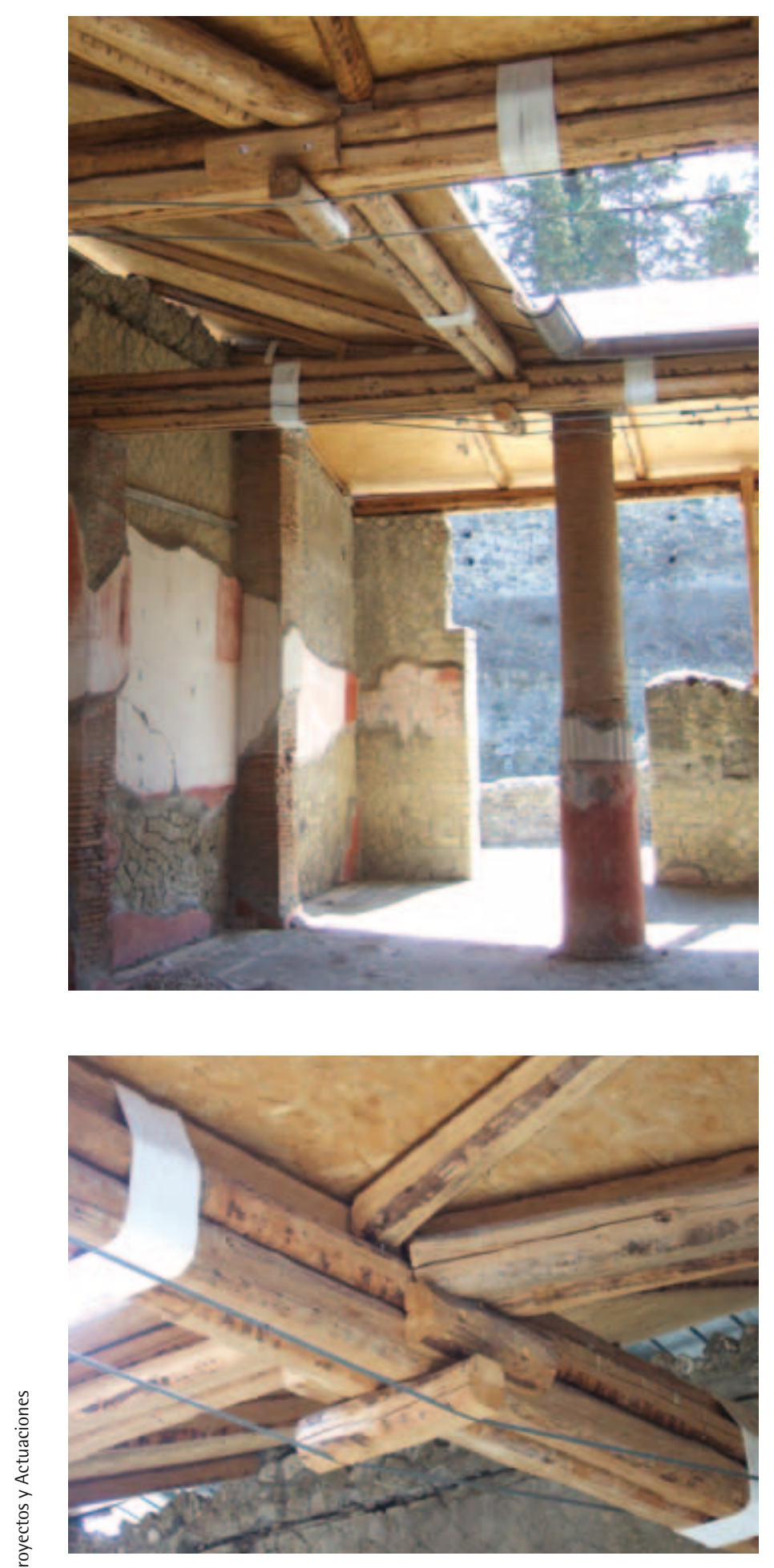

Herculaneum Conservation Project. Solución de las cubiertas en 2007. Fotos: Lucía Gómez Robles
Sin embargo esta decisión implicaba la obtención de las vigas de madera de la longitud y escuadría necesarias para salvar las grandes luces de los atrios romanos, lo que resultaba difícil y costoso. El equipo del HCP ideó entonces un sistema por el que, a partir de la utilización de pequeños rollizos de pocos metros y pequeña sección atados entre si y tensados con cables de acero, salvaban la luz con un coste reducido, utilizando el material original y con un sistema radical e inequivocamente actual.

Así que, con un solo gesto se recupera la imagen de la casa romana, sus tamizaciones lumínicas y su volumen espacial, imposibles de percibir sin la cubierta, aprovechando para ello la estructura existente y con un sistema constructivo absolutamente tradicional $y$, a la vez, radicalmente moderno, protegiendo las decoraciones interiores al reconducir el agua de lluvia, y al mismo tiempo del sol, y devolviendo la dignidad al edificio al evitar el aspecto de mutilación que, inevitablemente, conlleva la ausencia de una de sus partes fundamentales como es la cubierta.

Obviamente en este caso la recuperación de la función no es posible, pero la intervención permite entender mejor la funcionalidad original al visitante, y además no perjudica la comprensión histórica del edificio que conserva perfectamente las huellas de los daños causados por el Vesubio en el 79 a. de C. El entendimiento de la casa romana permite a su vez la profundización en la comprensión de la cotidianeidad de la población, algo normalmente complicado en civilizaciones tan antiguas y que en este caso se conoce gracias a la amplísima información obtenida tanto de Pompeya como de Herculano, y que convierte estos restos en un caso excepcional en la historia de la arquitectura.

Por tanto se recuperan los valores tipológico, estructural, constructivo y estético, se mejora la comprensión del funcional, obviamente sin llegar a recobrarlo y sin afectar al histórico, ni al formal, ni al simbólico, pero contribuyendo a su protección y por tanto a su conservación para el futuro.

\section{EL TEATRO DE ORANGE}

Otro caso de restauración actual es el teatro de Orange (MILLET, 2002; ASCHER, 2007; REPELLIN, 2006; 2007), uno de los teatros clásicos mejor conservados de toda Europa, en el que, no obstante, la ausencia de la cubierta había contribuido durante mucho tiempo a un progresivo deterioro del muro de la escena y de los pocos elementos decorativos que aún permanecen en ella.

La restauración realizada en 2003 consistió en la reposición de la cubierta de la escena con una estructura metálica y grandes láminas de vidrio con el objetivo fundamental de la preservación del frons scaenae de la acción de los agentes atmosféricos.

Sin embargo, la intervención en el teatro francés ha aportado mucho más que protección al edificio que con este añadido ha conseguido 

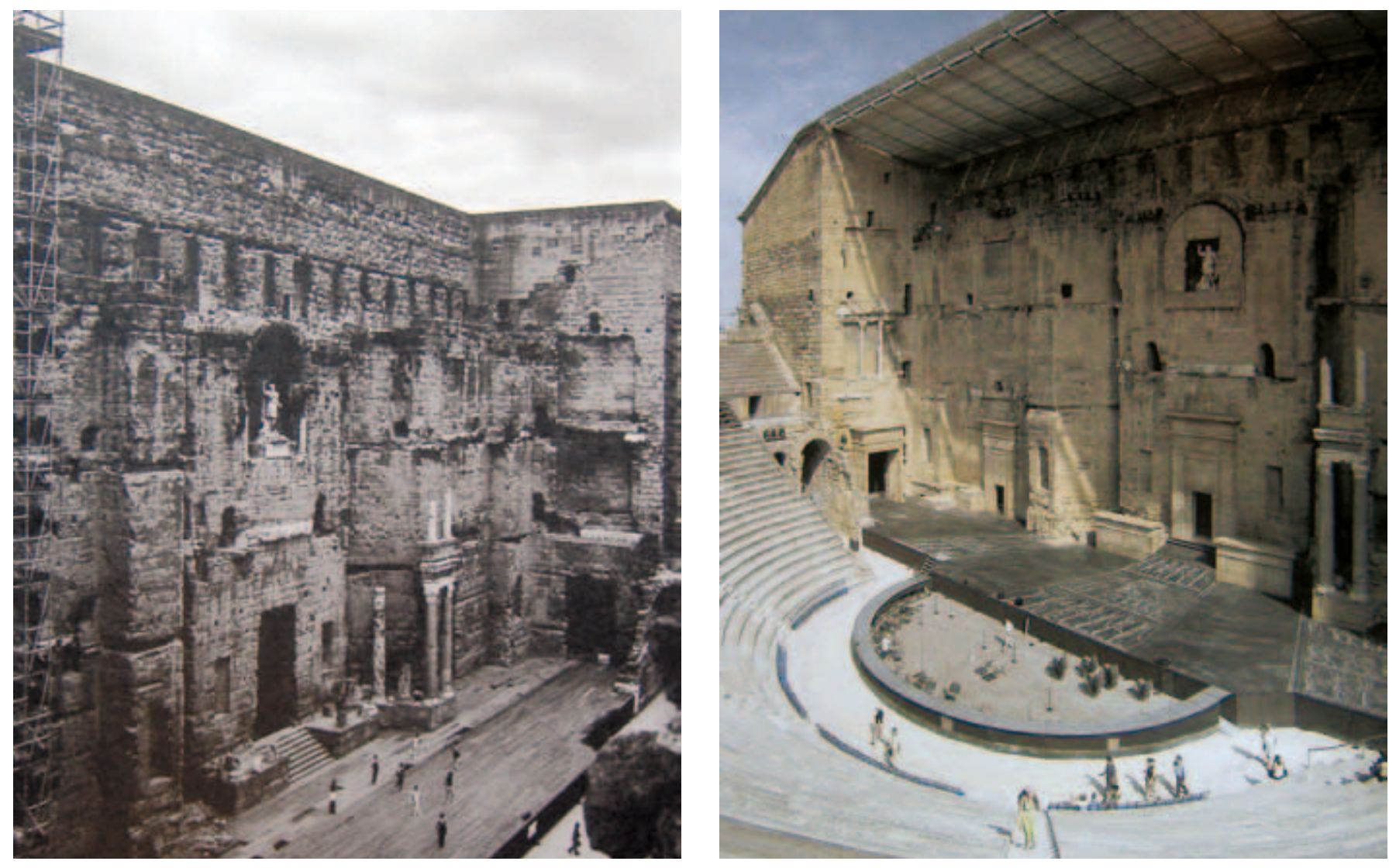

Teatro romano de Orange (siglo I d. de C.) antes y después de la restauración de 2003. Fuentes: MILLET, 2002: 21; REPELLIN, 2006: 38, respectivamente

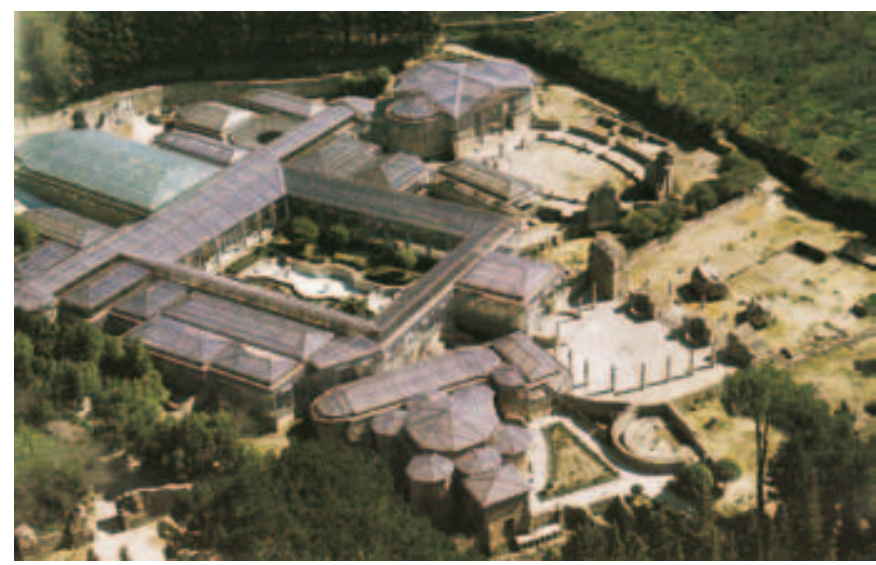

Imagen aérea de la Villa del Casale (siglo IV) en Piazza Armerina Fuente: SANTINI, 1993: 63

recuperar su imagen tipológica y su dignidad, alterando el aire de construcción mutilada que le otorgaba la ausencia de la cubierta, además de mejorar la funcionalidad de un edificio que continua sirviendo de marco a la dramaturgia clásica y moderna. Al mismo tiempo esta nueva estructura, de una forma muy similar a la que debió poseer el edificio original, se apoya, como aquélla, en los muros de la escena, reutilizando las poderosas fábricas clásicas y, por tanto, devolviéndole su original sentido constructivo y estructural.

La recuperación de las estructuras antiguas para su reutilización en las intervenciones actuales es precisamente uno de los problemas de la restauración actual, que rara vez permite a las construcciones antiguas ejercer el trabajo para el que fueron diseñadas, la mayor parte de las veces, con amplios márgenes de

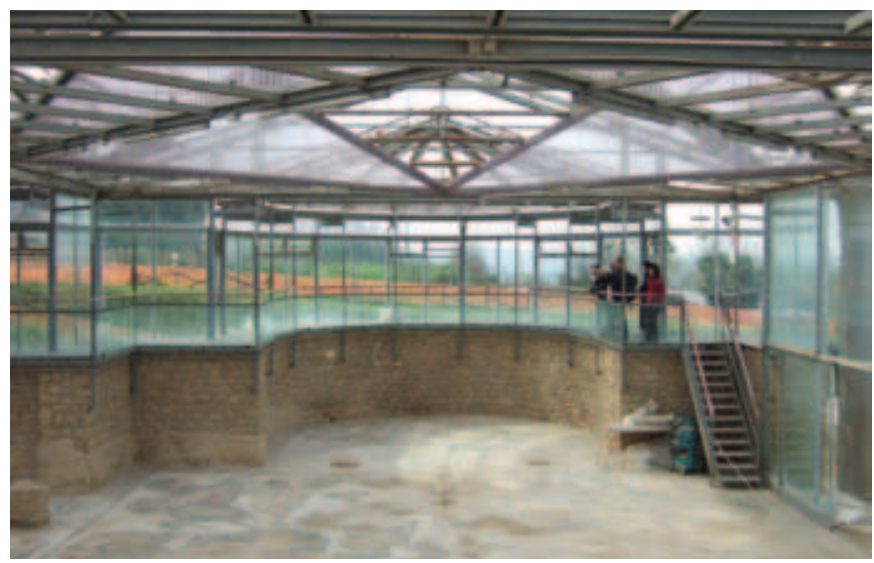

Interior del triclinium de la villa del Casale en Piazza Armerina con la cubierta de Franco Minissi. Foto: Lucía Gómez Robles

seguridad. La potente imagen de la escena de un teatro romano responde, además de a criterios de control de los espectadores del interior ${ }^{3}$ y la disposición de todo un aparato propagandístico del poder a través de la escultura, al hecho de tener que soportar la estructura en voladizo de la cubierta de madera, de un enorme peso y que generaba un importante momento flector sobre el muro de fondo del frons scaenae. La puesta en uso de nuevo de esa estructura le devuelve el sentido a los ojos del espectador y el conjunto recupera la coherencia.

En este caso, por tanto, la intervención recuperó los valores tipológico, funcional, estructural, constructivo, estético y simbólico, este último al mejorar la presencia del teatro potenciando su imagen, sin alterar ni el histórico ni el formal. 


\section{LA VILLA DEL CASALE, PIAZZA ARMERINA}

Para terminar no quiero olvidar un último ejemplo de mediados del XX no mencionado hasta este momento por su carácter controvertido, aunque su audacia y su fuerte intencionalidad merecen detenerse en él por lo que aporta a este análisis.

En la villa romana del Casale, del siglo IV d. de C., Franco Minissi realizó en la primera mitad del siglo XX (DEZZI BARDESCHI, 2008: 100) una impresionante restauración en la que reconstituia los volúmenes de la edificación conservada sólo en la parte baja de los muros, usando una estructura de hierro y vidrio que se apoyaba sobre los propios restos, dispuesta por la cara exterior y aprovechando el grosor de las fábricas para apoyar una pasarela que permitía recorrer la villa y admirar de ese modo sus magníficos mosaicos. La intervención consiguió recuperar la tipología, una imagen de una increíble potencia vista desde el aire, aunque la elección del material le hiciera perder claridad al nivel del suelo debido a la transparencia que impide la independencia de los espacios.

La reconversión en espacio museístico, sin embargo, y aunque la posición "sobre" los muros es completamente irreal desde el punto de vista del edificio original, no deja de ser ingeniosa, aunque suponga una visión poco natural de los mosaicos, tal y como estaban pensados. Además Minissi apoyó su estructura en los muros y columnas conservados aprovechándolos, aunque claramente falló en el material que ha convertido el espacio en un invernadero, húmedo y caluroso que no favorece en nada a la conservación de la decoración, perjudicando además a los visitantes.

En cualquier caso el intento es sugerente, y devuelve su estética a edificio, su dignidad, aunque sin recuperar las formas decorativas de los muros que no se conocen salvo en los pocos restos conservados, y potencia extraordinariamente el valor simbólico de la viIla, uno de los conjuntos arqueológicos romanos más importantes que se han conservado hasta nuestros días.

En este último ejemplo vemos cómo los fallos son numerosos empezando por el esencial de la conservación, pero tiene la virtud de recuperar el valor tipológico, aunque desde el aire, perdiendo toda la claridad a nivel del suelo; eso sí, recobra además el estético, el estructural, el constructivo, potencia el simbólico, y encuentra un nuevo valor funcional que no está reñido con el original, sin afectar a los valores estético y formal. En este caso, el simple cambio del material y una correcta ventilación convertirian la intervención en ejemplar, y con la opacidad ganaría, además de claridad y verosimilitud, unas condiciones lumínicas más apropiadas a la conservación y a la comprensión del edificio original.

\section{CONCLUSIONES}

Así que, vistas cada una de las restauraciones, se observa que todas contribuyen a aportar o reforzar valores del edificio que se encontraban perdidos o devaluados por efecto del paso del tiempo o la propia acción humana sobre ellos y a la vez mejoran la comprensión de los mismos, es decir, de algún modo "interpretan" el monumento. Y además lo consiguen con unas intervenciones que conceptualmente son de una extrema sencillez.

En realidad, en cada una de las restauraciones, no todos los valores se recuperan del mismo modo ni con la misma fuerza pero en todos los casos se logra restablecer varios de ellos, como hemos visto en el análisis anterior. Este pequeño estudio, no obstante, es un breve esquema de la aplicación del sistema de valores a las distintas restauraciones. Su desarrollo permite una profundización mucho mayor, excesiva para un artículo, que contribuye a contextualizar de forma muy concreta tanto el edificio como la intervención realizada sobre él en todos y cada uno de los ocho apartados expuestos. Por tanto téngase en cuenta que sólo se apunta la dirección del análisis aunque, en todo caso, este primer acercamiento ya ayuda a valorar la restauración con una cierta objetividad. De cualquier forma se ha pretendido extraer, al menos, la importancia aislada de los valores del edificio histórico ya que cada uno de ellos aporta información que ayuda a explicar el contexto de su origen y su historia posterior.

La importancia de la arquitectura no reside sólo en su validez como objeto en sí, sino en el enorme conjunto de datos que es capaz de aportar por su carácter de elemento de altísima complejidad. Desde este punto de vista se podría incluso releer la historia de la arquitectura, demasiado a menudo convertida en un listado de objetos más o menos situados cronológicamente, y acercarse a ella como a una fuente de información de múltiples matices ${ }^{4}$.

Por tanto, y volviendo a la conservación de edificios históricos, si todos los valores anteriores cualifican, explican y enriquecen al monumento, la restauración realizada sobre él será mejor cuantos más de esos valores contribuya a recuperar, porque percibimos con agrado cuándo esa restitución se produce. No obstante, Illevando al extremo la conservación a ultranza de uno de estos valores la restauración puede llegar a convertirse en una caricatura. Es la conjunción de todos ellos, o al menos la mayoria de ellos, la que aporta el equilibrio que percibimos en forma de amplia aceptación en las restauraciones anteriormente descritas.

Obviamente estos valores no tienen la misma importancia en todos los edificios ni es posible siempre recuperarlos en su totalidad, asi pues habrá que determinar en cada caso cuáles son los fundamentales para destacar o reforzar esos, sin anular para ello los demás ya que los valores que no se recuperan no deben, en ningún caso, verse mermados. Es el caso, por ejemplo, de los cambios de uso que deben ser compatibles con el propio edificio y no arruinar parte de aquellos valores en un afán de reutilización que acabe por volverlo irreconocible.

La determinación de esos valores fundamentales, en muchos casos, viene definida por el tipo de arquitectura que cada época rea- 
liza, que tiende a volcar sus esfuerzos en unos aspectos más que en otros. Como ejemplo se puede citar la arquitectura romana que depende fuertemente de su estructura, y es reconocible a través de ella a pesar de haber perdido todo rastro de ornamentación ${ }^{5}$, mientras que la arquitectura islámica nazarí depende absolutamente de su decoración ya que su estructura ligera se oculta siempre bajo la superficie decorada. En cualquier caso muchos de los valores adquiridos con el paso del tiempo, como el histórico o el simbólico, pueden llegar a ser predominantes en determinadas circunstancias.

Por tanto, para poder actuar sobre todos los valores y determinar cuáles son aquellos fundamentales es esencial conocer perfectamente el edificio en todos sus aspectos, por lo que resulta indispensable realizar el proyecto a la luz de la información de unos amplios estudios previos y tomar las decisiones sobre la intervención en función de todos los datos conocidos y correctamente valorados.

De cualquier modo y con todos los elementos anteriores sobre la mesa, la intervención no puede perder de vista que debe ir siempre encaminada a la protección y conservación del edificio histórico ya que, en caso contrario, se condena al monumento a su progresiva desaparición, lo que va en contra de la esencia misma de la restauración. No obstante se observa que las actuaciones orientadas a recuperar la estética del edificio suelen contribuir a su protección ya que el valor estético reside en los elementos fundamentales de la construcción que a su vez suelen ser los responsables de su conservación. De la misma forma la utilización de materiales fácilmente distinguibles del original y el carácter reversible forman en realidad parte de la salvaguarda del valor histórico del monumento.

Para terminar sólo añadiré que, evidentemente, todo lo anterior ni es un método rígido de intervención ni es un método de crítica cuantitativa que pueda utilizarse ponderando de 0 a 10 cada uno de los valores descritos para averiguar si el proyecto aprueba, suspende o saca nota. Nada más lejos de mi intención que simplificar tanto una disciplina tan compleja como la restauración. Pero sí creo que son elementos a tener en cuenta y que invitan a una reflexión más consciente en oposición a la "inspiración" que muchas veces se aplica tanto en el proyecto como en la crítica. Si hay un camino hacia una restauración científica, sin duda empezará justo ahí.

\section{Notas}

1 El fragmento de arco pertenece a un antiguo baño romano del conjunto arqueológico de Baalbek. Fue hallado y reconstruido en la década de 1960 por el ingeniero Haroutune Kalayan, a cargo de las excavaciones en Libano en aquel momento. La reconstrucción se realizó usando hormigón armado.

2 "Los expertos escucharon varias comunicaciones relativas al empleo de materiales modernos para la consolidación de los edificios antiguos, y han aprobado el empleo juicioso de todos los recursos de la técnica moderna, muy especialmente del concreto armado". Carta de Atenas, art. 5. http://www.mcu.es/patrimonio/docs/ MC/IPHE/Biblioteca/carta_de_atenas.pdf

${ }^{3}$ En los teatros romanos se originaban con frecuencia las revueltas populares, razón por la cual se erigían como estructuras cerradas que permitian aislar los disturbios en el interior.

${ }^{4}$ Para un análisis más profundo de la influencia del estudio de los valores en un caso concreto ver Gómez Robles; Quirosa García (en prensa).

${ }^{5}$ En cualquier caso es también cierto que nos hemos acostumbrado a ver la arquitectura romana despojada de su ornamentación que era, en realidad, profundamente rica. Quizás si las restauraciones realizadas sobre este tipo de edificaciones comenzaran a tener en cuenta de algún modo esa decoración, la imagen casi brutalista comúnmente extendida de la arquitectura romana podría llegar a percibirse de una forma completamente distinta.

\section{Bibliografía}

ASCHER, F. (2007) Toit en porte- à-faux pour un théâtre antique. Les Cahiers Techniques du Batiment, n² 266, 2007

DEZZI BARDESCHI, M. (2008) The work of Franco Minissi at the Roman Villain Piazza Armerina in danger. Heritage at Risk 2006/2007. ICOMOS World Report 2006/2007 on monuments and sites in danger. Altenburg (Germany): ReinholdVerlag, 2008

EPALZA, MIKEL DEL (1989) Baños Árabes en el País Valenciano. Valencia: Consellería de Cultura, Educaciò i Ciencia, 1989, p. 51

ESTEBAN CHAPAPRÍA, J. (2008) Leopoldo Torres Balbás, in memoriam. Papeles del Partal, no 4, 2008, pp. 81-94

FICACCI, L. (2006) Piranesi. Madrid: Taschen, 2006

GALLEGO BURÍN, A. (1996) Granada. Guía artística e histórica de la cuidad. Granada: Comares, 1996

GÓMEZ ROBLES, L.; QUIROSA GARCÍA, V. (en prensa) Dos lanzas por Sagunto. Cara y cruz de una restauración. Actas de la IV Bienal de Restauración Monumental. 25 años de Restauración Monumental (1925-2000), 22-25 enero de 2009 (en prensa)

GONZÁLEZ MORENO-NAVARRO, A. (2010) ¿Hubo alguna vez una "restauración a la española"? Actas de la IV Bienal de Restauración Monumental. 25 años de Restauración Monumental (1925-2000), 22-25 enero de 2009 (en prensa) GROS, P. (2001) L'archittectura romana dagli inizi del III secolo a.C. alla fine dell'alto Impero. Milán: Longanesi\&C, 2001, p. 451

JONSSON, M. (1986) La cura dei monumenti alle origini. Restauro e scavo di monumenti antichi a Roma (1800-1830). Stockholm: Svenska Institutet i Rom, 1986 LUCIANI, R. (1990) // Colosseo. Novara: DeAgostini, 1990

MILLET, B. (2002) Le patrimoine antique de Provence-Alpes-Côte d'Azur. Monumental 2002. Revue scientifique et technique des monuments historiques. Éditions du patrimoine, 2002, pp. 20-23

PESARESI, P.; RIZZI, G. (2007) New and existing forms of protective shelter at Herculaneum: towards improving the continuous care of the site. Conservation and Management of Archaeological Sites, 2007, vol. 8, pp. 237-252

REPELLIN, D. (2006) Théatre antique d'Orange: couverture de la scène. Architecture méditerranéenne, n. 63, décembre, 2006, pp. 36-39

REPELLIN, D. TRICAUD, É.; CHEVAL, N. (2007) La toiture de scène du théâtre d'Orange. Monumental: revue scientifique et technique des monuments historiques, semestriel 2, décembre. Éditions du patrimoine, 2007, pp. 50-53 SANTINI, L. (1993) Immagini di Sicilia dal cielo. Narni-Terni: Plurigraf, 1993 TESTA, F. (1996) Conservare per imitare. Pavia: Cyrano, 1996 TORRES BALBÁS, L. (1965) Diario de obras de la Alhambra: 1923. Cuadernos de la Alhambra, n 1, 1965

TORRES BALBÁS, L. (1982) Las casas del Partal. Obra dispersa I. Al-Andalus. Crónica de la España musulmana, nº 4. Madrid: Instituto de España, 1982 